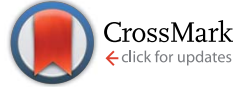

Cite this: J. Mater. Chem. B, 2015, 3, 2583

Received 21st November 2014 Accepted 30th January 2015

DOI: $10.1039 / c 4 t b 01928 h$

www.rsc.org/MaterialsB

\section{A 'soft spot' for drug transport: modulation of cell stiffness using fatty acids and its impact on drug transport in lung model}

\author{
Mehra Haghi, ${ }^{\text {ab }}$ Daniela Traini, ${ }^{\text {ab }}$ Lisa G. Wood, ${ }^{\text {e }}$ Brian Oliver, ${ }^{\text {af }}$ Paul M. Young ${ }^{\text {ab }}$ \\ and Wojciech Chrzanowski*cd
}

The impact of a polyunsaturated fatty acid, arachidonic acid (AA), on membrane fluidity of epithelial cells and subsequent modulation of the drug transport was investigated. Membrane fluidity was assessed using molecular force microscopy. Calu-3 human bronchial epithelial cells were cultured on Transwell $\circledast$ inserts and the cell stiffness was assessed in the absence of fatty acids or in the presence of $30 \mu \mathrm{M} \mathrm{AA}$. The morphology of the epithelial cells was distinctly different when AA was present, with the cell monolayer becoming more uniform. Furthermore the cell stiffness and variation in stiffness was lower in the presence of AA. In the fat-free medium, the median cell stiffness was $9.1 \mathrm{kPa}$ which dropped to $2.1 \mathrm{kPa}$ following exposure to AA. To further study this, transport of a common $\beta 2$-agonist, salbutamol sulphate (SS) was measured in the presence of $A A$ and in a fat free medium. The transport of SS was significantly higher when AA was present $(0.61 \pm$ $0.09 \mu \mathrm{g}$ versus $0.11 \pm 0.003 \mu \mathrm{g}$ with and without $A A$ respectively). It was evidenced that AA play a vital role in cell membrane fluidity and drug transport. This finding highlights the significance of the dietary fatty acids in transport and consequentially effectiveness of medications used to treat pulmonary diseases such as asthma.

\section{Introduction}

In recent years there has been growing public awareness of the potential health effects of dietary fatty acids. Much attention has focused on the inflammatory effects of fatty acids and their

${ }^{a}$ Woolcock Institute of Medical Research, The University of Sydney, NSW 2037, Australia

${ }^{b}$ Discipline of Pharmacology, Faculty of Medicine, The University of Sydney, NSW 2006, Australia

${ }^{c}$ Faculty of Pharmacy, The University of Sydney, NSW 2006, Australia. E-mail: wojciech.chrzanowski@sydney.edu.au

${ }^{d}$ Department of Nanobiomedical Science \& BK21 PLUS NBM Global Research Centre for Regenerative Medicine, Dankook University, Cheonan 330-714, Republic of Korea ${ }^{e}$ Centre for Asthma and Respiratory Diseases, Hunter Medical Research Institute and The University of Newcastle, NSW, 2305, Australia

${ }^{f}$ School of Medical \& Molecular Biosciences, University of Technology Sydney, NSW, 2007, Australia contribution to the development of chronic inflammatory diseases. Another effect of fatty acid intake is modification of cell membrane composition, which consequently alters cell membrane properties. Polyunsaturated fatty acids (PUFA) are important structural components of cell membranes. When incorporated into phospholipids they affect cell membrane properties such as fluidity, flexibility, permeability and the activity of membrane bound enzymes. ${ }^{1,2}$ Recently, a study by Wood, ${ }^{3}$ has investigated the effect of a high fat mixed meal in asthma. In this study subjects that consumed a high fat meal, containing both saturated and PUFAs, experienced reduced bronchodilator response to salbutamol sulphate. While factors such as increased adrenalin production and subsequent $\beta 2$-adrenoceptor desensitisation may play a potential role in this reduced response, it is also likely that large changes in systemic fatty acid concentrations may have effects on the cell membranes of the airway epithelium, which may affect bronchodilator transport.

At the cellular level, the function of a cell is closely linked to its structure. The cell cytoskeleton, to a large extent, is responsible for the structural and mechanical integrity of cells and takes an active role in signalling pathways (i.e. mechanotransduction). Thus, any changes in the cell structure will result in changes to the mechanical properties of the cell and consequently its functionality. Hence, the ability to measure mechanical properties of cells at different levels, in particular the nano-level, might be considered a powerful method to assess cell and tissue functionality. Recently, there has been a significant increase in number of studies investigating mechanical properties of cell/tissue. ${ }^{4-8}$ Investigations of the impact of diverse physiological conditions on the mechanical properties of various cells, expressed mainly as stiffness, and quantified by the Young's modulus has given us a new understanding of the cell; leading to discoveries of complex pathways that govern cell responses and functionality..$^{\mathbf{9} 10}$

Studies have shown that membrane fatty acids can be modified during short-term culture in lipid-restricted medium, enriched with particular fatty acids. ${ }^{11}$ AA is found in high concentrations in eggs and meat, and is highly prevalent in 
westernised fast foods, such as the foods consumed in the clinical study on which these in vitro experiments are based. ${ }^{\mathbf{1 2}}$ AA is very important for membrane function, as mammalian cells and tissues contain substantial amounts of AA (up to $25 \%) .{ }^{13}$ This fatty acid is an amphipathic molecule, its hydrophobic tail remains in the lipid bilayer while the hydrophilic end merges in the aqueous environment of the cell. ${ }^{14}$ The high prevalence of AA under physiological conditions explains the essentiality of this molecule in biochemical reactions; AA is a precursor to leukotrienes, prostaglandins, and thromboxane. ${ }^{\mathbf{1 4}}$

One of the techniques used for assessment of membrane function in this study was atomic force microscopy (AFM). This is one of the scanning probe microscopy techniques, which allows for precise 3D imaging of samples, and probing of mechanical properties. ${ }^{15}$ AFM is equipped with a flexible cantilever with a sharp tip or spherical colloidal probe. When the tip/probe is brought in close proximity to the sample surface, forces between the tip/probe and the sample lead to deflection of the cantilever. The deflection is measured using a laser spot reflected from the top of the cantilever surface to a position sensitive photo diode detector. For cell biology applications, the probe is mounted on a piezoelectric scanner and as the probe is moved relative to the stationary sample, interactions between the tip/probe and the sample change the position of the laser reflection, which is the measure of the interactions (indentation, force, separation). The data obtained is then translated into a two dimensional map of e.g. stiffness that corresponds with three-dimensional image of the surface topography. ${ }^{6,16,17}$

We hypothesised that epithelial cells incubated with AA, could incorporate AA into the cell membrane, modifying cell stiffness and thus permeability. Therefore, the aim of this study was to investigate the role of AA on membrane stiffness, fluidity and transport of salbutamol sulphate, a commonly used $\beta 2$-agonist asthma drug, across Calu-3 bronchial epithelial cells.

\section{Materials and methods}

\subsection{Calu-3 cell culture}

Calu-3 cell line (HTB-55) was purchased from the American Type Cell Culture Collection (ATCC, Rockville, USA). The cells (passage 35-40) were grown in $75 \mathrm{~cm}^{2}$ flasks in Ham's F-12 with the following growth supplements: epidermal growth factor $0.5 \mathrm{ng} \mathrm{ml}^{-1}$, bovine pituitary extract $50 \mu \mathrm{g} \mathrm{ml}^{-1}$, hydrocortisone $0.5 \mu \mathrm{g} \mathrm{ml}{ }^{-1}$, epinephrine $0.5 \mu \mathrm{g} \mathrm{ml}^{-1}$, transferrin $10 \mu \mathrm{g} \mathrm{ml}^{-1}$, insulin $5 \mu \mathrm{g} \mathrm{ml}^{-1}$, retinoic acid $0.1 \mathrm{ng} \mathrm{ml}{ }^{-1}$, triiodothyronine $6.5 \mathrm{ng} \mathrm{ml} \mathrm{m}^{-1}$ (Sigma, MO, USA). Cells were maintained in a humidified $95 \%$ air $5 \% \mathrm{CO}_{2}$ atmosphere of at $37{ }^{\circ} \mathrm{C}$ and were propagated according to ATCC recommendations.

Cells were seeded onto 24 well Transwell polyester inserts $\left(0.33 \mathrm{~cm}^{2}\right.$ polyester, $0.4 \mu \mathrm{m}$ pore size) (Corning Costar, MA, USA) at a density of $5 \times 10^{5}$ cells per $\mathrm{cm}^{2}$ with $100 \mu \mathrm{L}$ and $500 \mu \mathrm{L}$ of the above-mentioned fat-free medium in the apical and basolateral compartment, respectively. The culture was fed every alternate day with fresh medium. The monolayers were allowed to form over 12-14 days as determined by Mamlouk. ${ }^{18}$ After this period, the cells were used for transport study.

\subsection{Barrier integrity studies}

Barrier integrity of Calu-3 cells was before and after treatment with $30 \mu \mathrm{M}$ AA (in the basal chamber) was assessed by measuring the transepithelial electrical resistance (TEER) of the cells using an EVOM Voltohmmeter (World Precision Instruments, FL, USA) with STX-2 chopstick electrodes according to the method described by Haghi. ${ }^{19}$ Furthermore, the permeability to paracellular marker, fluorescein sodium (flu-Na) (Sigma-Aldrich, Sydney, Australia) (MW $0.367 \mathrm{kDa}$ ) was also measured after incubation with AA $30 \mu \mathrm{M}$, as described previously by Haghi. ${ }^{19}$

\subsection{Cell viability assay}

The toxicity of arachidonic acid (20:4, n-6; AA) (Cayman Chemicals, Michigan, USA) was assessed by measuring the viability of Calu-3 cells in a liquid covered culture, following 24 hours drug exposure to increasing concentrations of AA (1-100 $\mu \mathrm{M})$. Calu-3 cells were seeded into a 96 well plate and incubated overnight at $37{ }^{\circ} \mathrm{C}$ in $5 \% \mathrm{CO}_{2}$ atmosphere. After 24 hours, increasing concentrations of AA was added to each well (final ethanol concentration $\leq 1 \%$ in each well). The plate was incubated for 24 hours after which the cells were analysed for cell viability. Briefly, $20 \mu \mathrm{L}$ of CellTiter $96{ }^{\circledR}$ Aqueous assay (MTS reagent) (Promega, Madison, USA) was added to each well and the plates incubated for 3 hours at $37^{\circ} \mathrm{C}$ in humidified $5 \%$ $\mathrm{CO}_{2}$ atmosphere. Absorbance was measured at $490 \mathrm{~nm}$ using a spectrophotometer and associated software (Spectramax M2 and Soft Max pro 4.8, Molecular Devices, Sunnyvale, CA, USA) and the value was directly proportional to cell viability (\%). The half maximal inhibitory concentration $\left(\mathrm{IC}_{50}\right)$ values were defined as the drug concentration that produced a decrease of $50 \%$ in cell viability compared to the untreated control.

\subsection{Salbutamol sulphate transport study}

To study the effect of AA on transport of Salbutamol sulphate (SS) (S \& D Chemicals, Sydney, Australia), after 12-14 days in culture, Calu-3 cells were treated with AA, which was dissolved in ethanol at $6 \mathrm{mM}$ and further, diluted in HBSS to give final experimental concentrations of $30 \mu \mathrm{M}$ in the basolateral chamber only. Cells were equilibrated with AA for 60 minutes in a humidified atmosphere of $95 \%$ air $/ 5 \% \mathrm{CO}_{2}$ at $37{ }^{\circ} \mathrm{C}$ prior to addition of SS. Following fatty acid incubation period, SS $(100 \mu \mathrm{M})$ in Hanks's buffer salt solution (HBSS) (Invitrogen, Sydney, Australia) was added to the apical chamber. Samples of $100 \mu \mathrm{L}$ were taken every 30 minutes from the basal chamber and the amount was replaced with fresh HBSS. Amount of SS transported over time for both control (fat-free) cells and cells exposed to AA was measured by high performance liquid chromatography (HPLC).

\subsection{High performance liquid chromatography}

Analysis of SS was conducted using a Shimadzu Prominence UFLC system equipped with an SPD-20A UV-Vis detector (operating at $276 \mathrm{~nm}$ ), LC-20AT solvent delivery unit, SIL-20A HT Autosampler (Shimadzu Corporation, Japan) and NovaPak 
C18 column $(5 \mu \mathrm{m}, 150 \times 3.9 \mathrm{~mm})$ (Waters Corporation, Massachusetts, USA). The mobile phase was a mixture of methanol $(60: 40 \%, \mathrm{v} / \mathrm{v}): 0.1 \% \mathrm{w} / \mathrm{v}$ aqueous sodium dodecyl sulphate solution. The flow rate was $1 \mathrm{ml} \mathrm{min}^{-1}$ and injection volume was $100 \mu \mathrm{L}$. Standard linearity was obtained between 0.1 and $50 \mu \mathrm{g} \mathrm{ml}^{-1}\left(R^{2}=0.9999\right)$ with a retention time of approximately 5 minutes.

\subsection{Cell morphology and stiffness measurements}

Calu-3 cells were seeded on Transwell cell culture inserts at density $5 \times 10^{5}$ cells $\mathrm{cm}^{-2}$ and cultured for 12-14 days. Following 1 hour incubation with $30 \mu \mathrm{M}$ AA (basal chamber only), the Transwell membranes were cut off and attached to the bottom of the biocell (close fluid cell) and incubated in $\mathrm{CO}_{2}$ independent cell culture media. To investigate the influence of lipid on the cell stiffness, which is related to the cell membrane structure and permeability, cells were probed/indented using (MFP-3D-Bio, AssylumResearch, Santa Barbara, CA, USA).

Stiffness of cells was measured by determining the elastic modulus ( $E$ ) (Young's modulus). The cells were located using light microscope and then imaged in contact mode using silicon nitride lever TR400PSA (Olympus, Tokyo, Japan); probes spring constant was measure using thermal method and it was between 0.064 and $0.072 \mathrm{~N} \mathrm{~m}^{-1}$. Next, the probe was lowered at the speed of $10 \mathrm{~nm} \mathrm{~s}^{-1}$ onto the cell and pressed/probed until threshold cantilever deflection $(20 \mathrm{~nm})$ was obtained. The deflection of the cantilever was plotted against the movement of piezo in the $z$-direction, which gave the force curves. Force curves were obtained at various locations and fit to the Hertz model. ${ }^{20}$ To extract the Young's modulus following equation was used: $:^{17,21,22}$

$$
F_{\text {cone }}=\frac{2}{\pi} \frac{E}{\left(1-v^{2}\right)} \tan (\alpha) D^{2}
$$

where, $(\alpha)$ is the semi included angle of the cone tip, $(R)$ is the sphere radius, and $(v)$ is the poisson's ratio which usually assumes a value of $v=0.5$ for cells.

Maps of stiffness (force maps) were recorded for the samples before and after incubation in fatty acid solution. For each sample, at least six different locations were probed and maps were recorded at resolution $64 \times 64$ points. Data was processed to produce lognormal cumulative-stiffness plots where percentile stiffness values could be calculated.

\subsection{Statistical analysis}

Data were subjected to statistical analysis using the SPSS Statistics 17.0 software package (SPSS Inc, Chicago, Illinois, USA). Student's paired $T$ test was utilised to test for significance. Difference was considered significant when $p<0.05$.

\section{Results}

\subsection{Cell viability assay}

The dose response cytotoxicity profile of AA on Calu-3 cells was investigated as described in a previous study by Scalia. ${ }^{23}$ Calu-3 cell cultures were exposed to a range of AA concentrations (from a minimum of $1 \mu \mathrm{M}$ to a maximum of $100 \mu \mathrm{M}$ ) over a 24 hours treatment period. Cells viability was calculated with reference to the untreated cells, where average absorbance was normalised to $100 \%$ viability. The viability assay demonstrated that cells treated with AA had $50 \%$ cell viability at a concentration of 68.75 $\pm 4.72 \mu \mathrm{M}\left(\mathrm{IC}_{50}: 69 \mu \mathrm{M}\right)$. Furthermore, viability of Calu-3 cells following incubation with $30 \mu \mathrm{M} \mathrm{AA}$, was shown to be $85 \pm 12 \%$.

\subsection{TEER and flu-Na permeability assessment}

TEER values before and after incubation with AA were measured $844 \pm 79 \Omega \mathrm{cm}^{2}$ and $511 \pm 63 \Omega \mathrm{cm}^{2}$, respectively. The apparent permeability value (papp) of Calu-3 cells grown in the fat-free culture media increased from $9.70 \times 10^{-8} \pm 4.70 \times 10^{-8}$ to 2.42 $\times 10^{-7} \pm 6.46 \times 10^{-8} \mathrm{~cm} \mathrm{~s}^{-1}$ using a paracellular flu-Na permeability assay. The findings indicate a significant decrease in the barrier integrity values measured following incubation with the fat. However, despite the significant decrease, the results indicated suitable barrier integrity for the transport studies.

\subsection{Calu-3 epithelial transport study}

After addition of SS to the apical chamber, the concentration of SS transported to the basal chamber was measured at set time points and the cumulative mass transport was calculated. The cumulative amount of SS transported over 4 hours across cells in the fat-free transport buffer and following the incubation of the cells with $30 \mu \mathrm{M}$ of AA for one hour was measured. Analysis of data suggested that bronchodilator transport was significantly higher in the presence of AA in comparison to the transport rate of the cells incubated in the fat-free transport buffer $(0.61 \pm 0.09 \mu \mathrm{g}$ versus $0.11 \pm 0.003 \mu \mathrm{g}$, Student's paired $T$ test, $P<0.05$, with and without AA respectively) - Fig. 1 . This result suggests the essentiality of the AA PUFA for membrane fluidity has been further confirmed by the decreased apparent permeability (papp) in the fat-free culture media (papp changed from $9.70 \times 10^{-8} \pm 4.70 \times 10^{-8}$ in the fat-free medium to $2.42 \times 10^{-7} \pm 6.46 \times 10^{-8} \mathrm{~cm} \mathrm{~s}^{-1}$ ) using the paracellular flu-Na permeability assay.

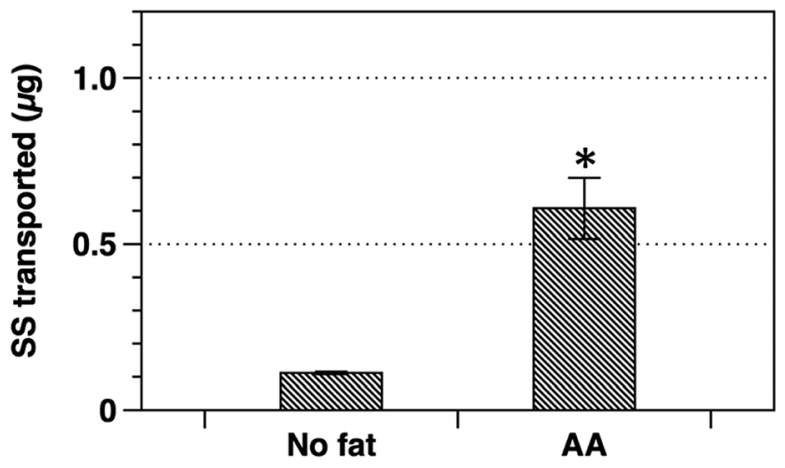

Fig. 1 The cumulative amount of SS transported over 4 hours across cells in the fat-free transport buffer and following the incubation of the cells with $30 \mu \mathrm{M}$ of $\mathrm{AA}$ for one hour. 


\subsection{Calu-3 cell morphology and stiffness measurements}

The analysis of cell surface morphology by MFP revealed differences when cells were incubated with AA (see Fig. 2 for representative topographical images). For each type of sample, control and incubated with lipid solution, a minimum of three different samples were scanned and on each sample minimum of three regions $(50 \times 50 \mathrm{um})$ was scanned and probed. In addition multiple samples were produced in different days and scanned/probed to reduce the possibility of day dependent
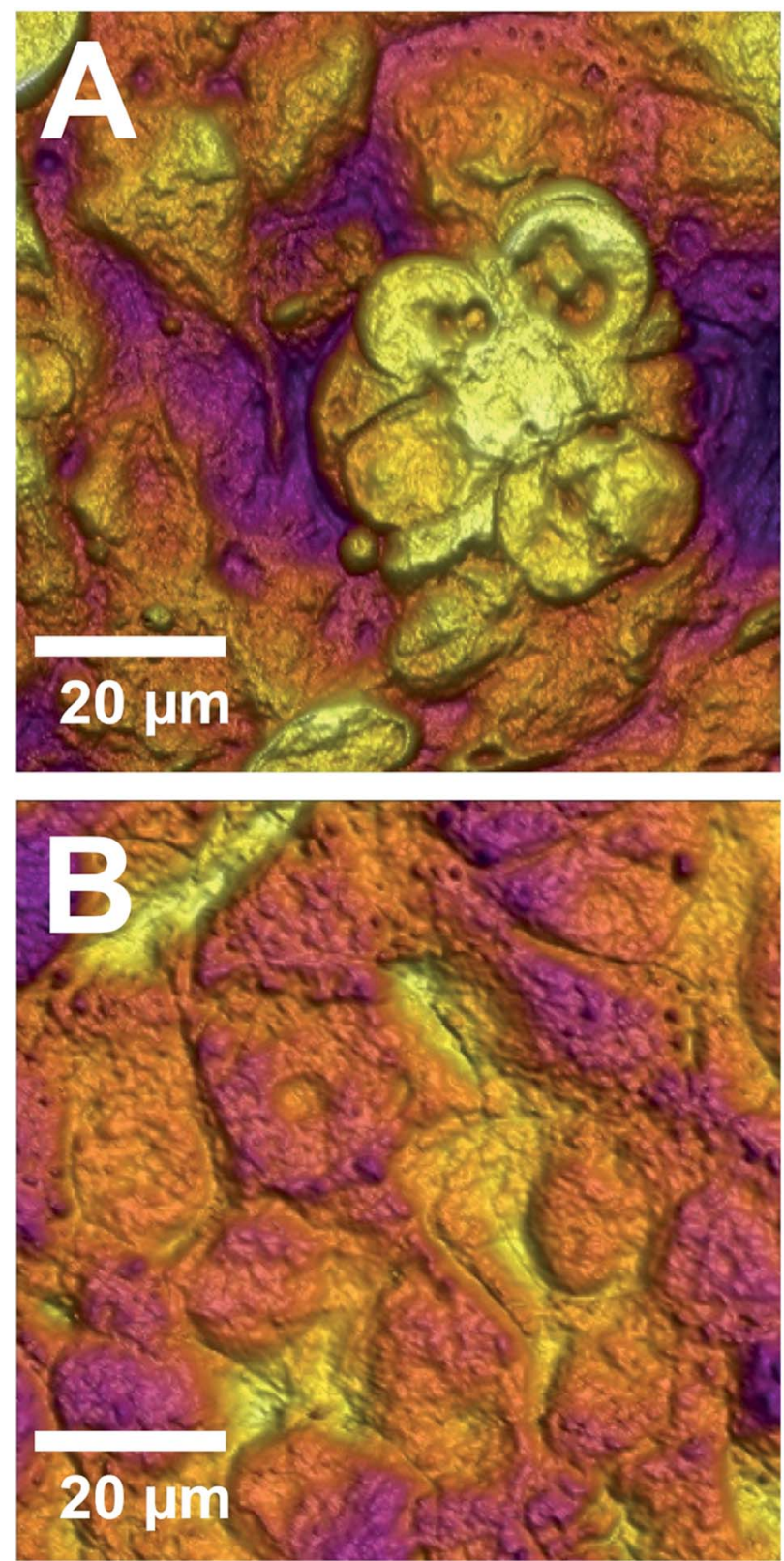

Fig. 2 Effect of arachidonic acid on the morphology of Calu-3 cells. Cell morphology before (A) and after (B) incubation in solution of arachidonic acid (AA). Cells before incubation in AA showed 'dense' morphology with distinct borders between the cells and several clusters of cells. Cells after incubation in AA showed flattened morphology. Clusters were not distinguishable and the cells' surface appeared as a more uniform monolayer. results (e.g. due to cell cycle). Cells before incubation in AA showed 'dense' morphology with distinct borders between the cells and several clusters of cells. Cells after incubation in lipid solution showed flattened morphology. Clusters were not distinguishable and the cells' surface appeared as more uniform monolayer.

Cells produce morphological diverse monolayer with several underling structural components (e.g. cell membrane, cytoskeletal components, actin fibers, nuclei, tight junction), which is the main reason for spread of the stiffness. These effects (distribution of stiffness) are expected because cell is composite structure. By detecting changes to its stiffness, it is possible to evaluate changes to its make-up and function. Here, by scanning and analysis many samples statistical analysis was possible and presented data demonstrated clearly effects of the incubation on stiffness of the cells. Side-by-side topographical and stiffness maps of the cells before and after exposure to AA are shown in Fig. 3. It can be seen from the scale bars that both the height distribution and cells stiffness was lower in the case of the AA treated cells. These images allow easy, visual identification of uniformity of stiffness distribution and enable visualizing correlation between topographical features and stiffness (e.g. tight junction that showed greater stiffness Fig. 3B).

To study this characteristic further, stiffness values across the surface of the epithelia from samples before and after exposure to AA were exported as an array and processed to form histograms as shown in Fig. 4A and B, respectively. Presented histograms show frequency and distribution of stiffness (how often specific stiffness value was encountered on the sample) across entire scanned surface and inserted figures present exact location of specific stiffness on the samples when overexposed on the topography.

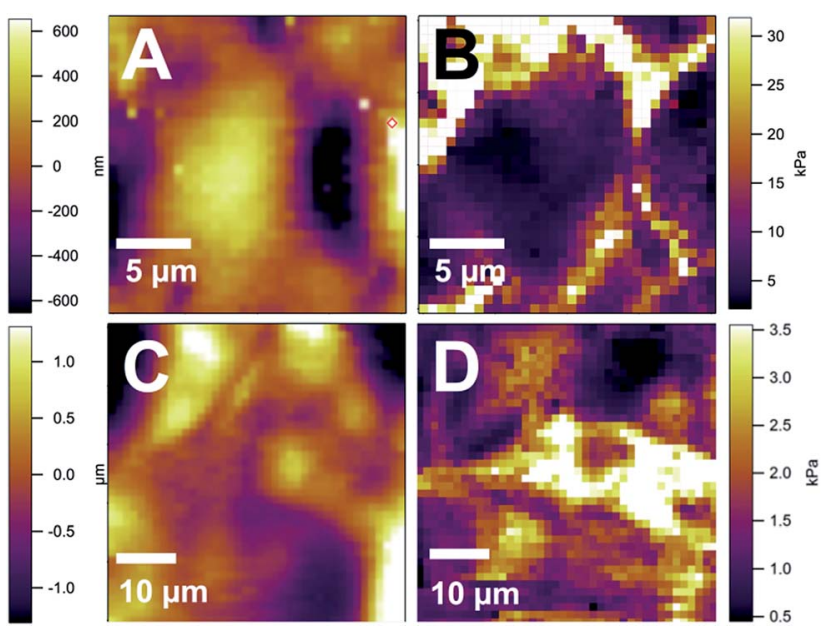

Fig. 3 Atomic force microscopy of Calu-3 cells. Morphology and distribution of the cell stiffness obtained using molecular force microscopy before (A and B) and after ( $C$ and D) incubation in arachidonic acid solution: (A) morphology of the samples - height map that represents 3D structure of the cells and (B) distribution of the stiffness - Young's modulus map that demonstrates regions of high and low stiffness of the cells before incubation in the lipid solution; (C) morphology of the cells and (D) the distribution of the cell stiffness following incubation in arachidonic acid solution. 
The analysis of cell stiffness showed that the incubation with AA resulted in significant decrease in stiffness. The maximum values of Young's modules for cells before incubation were $\sim 50 \mathrm{kPa}$. The stiffness varied across the cells and ranged from 5-50 kPa. After incubation with AA solution the maximum values of Young's modules distinctly decreased to $\sim 3.5 \mathrm{kPa}$. The majority of the stiffness values across the cells ranged from 0.5 and $3.5 \mathrm{kPa}$ with some higher values observed. The distribution of stiffness across the samples was expected and was associated with cell make-up and presence of underlying cellular structures such as cytoskeleton and nuclei, which influence the stiffness.

To quantify the stiffness of the cells in the fat free medium and AA treated cells, the data was subjected to a lognormal regression analysis as a plot of cumulative count $v s$. stiffness. In order to generate this plot, the matrix of 4096 stiffness values measured across the cells were converted into a histogram (percent stiffness values within defined bins) which could then be plotted (Fig. 5).

Regression analysis between 15-85\% cumulative values had a good fit with $R^{2}$ values of 0.97 and 0.99 for fat-free and AA treated cells, respectively. Regression across 5-95\% of the data range resulted in slightly lower regression coefficients ( 0.93 and 0.98 for the fat-free and AA treated samples), specifically due to
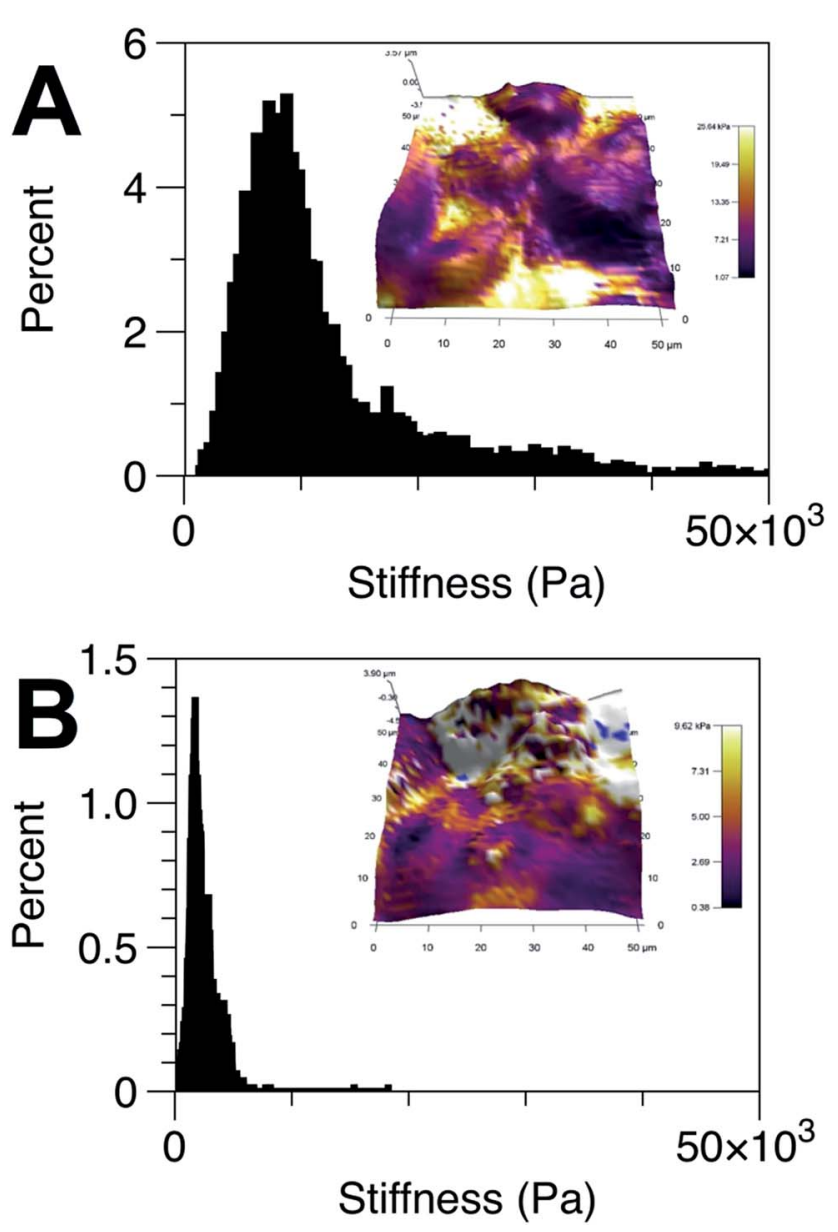

Fig. 4 Effect of arachidonic acid on Calu-3 map of stiffness. Map of the stiffness for (A) no fat and (B) arachidonic acid incubated cells with corresponding histograms of stiffness distribution.

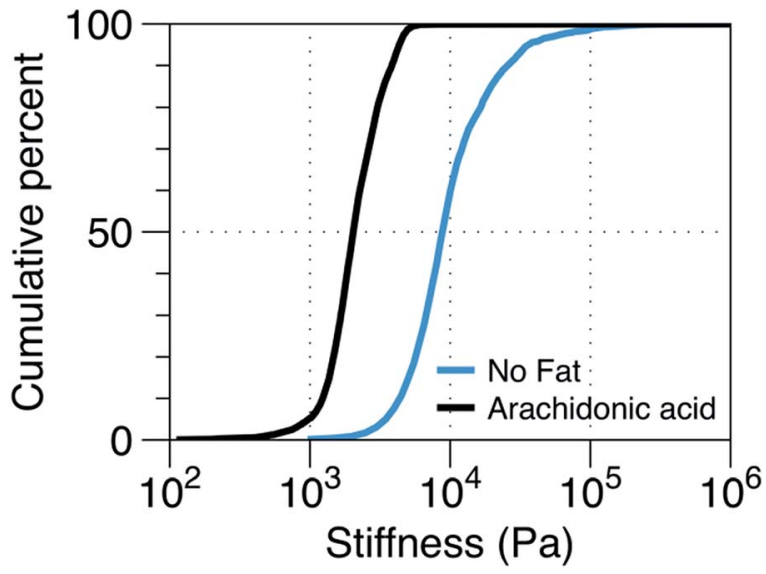

Fig. 5 Cumulative log-stiffness of Calu-3 cells. Cumulative log-stiffness distributions for cell surfaces with no fat media and arachidonic acid media. $N=4096$ data points over $50 \times 50$ area.

the high stiffness value tailing in the samples of the fat-free medium (presumably due to increased irregularity in the structure on the surface).

Regression analysis of the 15-85\% cumulative data gave median stiffness values $\left(S_{0.5}\right)$ of $9.1 \mathrm{kPa}$ for the cells before exposure to fat and $2.1 \mathrm{kPa}$ after incubation with AA. Additionally the $16^{\text {th }}$ and $84^{\text {th }}$ percentile values were calculated and used to calculate the geometric standard deviation (GSD) using the following equation:

$$
\mathrm{GSD}=\left[\frac{S_{0.84}}{S_{0.16}}\right]^{1 / 2}
$$

In general, the GSD decreased from 1.9 to 1.5 with addition of AA to the media. Such observations suggest that the cell surface not only becomes less stiff but more uniform in-terms of its stiffness. Such observations were in good agreement with the morphological changes observed using MFP microscopy.

\section{Discussion and conclusions}

The findings of this study suggest that the presence of AA, an n-6PUFA, is an essential component for membrane fluidity and therefore transport of SS. This finding has been further confirmed by the decreased permeability in the fat-free culture media. Fatty acid composition has an important role in cellular structure and function. Short-term exposure to elevated levels of unsaturated exogenous fatty acids mediates membrane perturbations while saturated fatty acids are relatively inert. This has generally been related to the differential effect of these fatty acids on cell membrane structure. The incorporation of PUFAs in membrane phospholipids modulates membrane structure, fluidity and function, ${ }^{\mathbf{1 2 4 - 2 6}}$ due to the presence of cis-double bonds. These cis-double bonds induce molecular conformations in the molecule that increase with the number of double bonds and prevent the chain from adopting a rigid extended configuration, ${ }^{24}$ leading to coiling of the structure. ${ }^{27}$ PUFAs possess a 
great variety of conformations and, due to the coiling, cause a bigger separation of the bilayer. This can decrease the packing of the membrane and makes it more fluid. ${ }^{28}$ In this study, it was observed that cell membranes and hence the transport of SS, is sensitive to alterations in the fatty acid environment.

PUFA are those fatty acids, which contain two or more double bonds in their carbon chain. They can be further classified as n-3 or n-6PUFA, depending on the position of the double bonds. Previous studies have examined the role of both n-3 and n-6PUFA in cell membranes. ${ }^{1}$ However, our experiments have focused on AA, an n-6PUFA. We chose this fatty acid, because in the clinical study on which this work was based, there were significant concentrations of AA present and an absence of n-3PUFA, which is typical of fast food diets. ${ }^{25}$ The results presented in the current study suggest that impaired bronchodilator efficacy that occurs following consumption of a high fat meal is not due to n-6PUFA inhibition of bronchodilator transport into the epithelium. ${ }^{25}$ Furthermore, while some studies report that salbutamol is transported by the paracellular pathway. ${ }^{29}$ Some studies have indicated that organic cationic transporters (OCTs) are also involved in the process. ${ }^{30}$ In the present study transport of SS following incubation with $20 \mu \mathrm{M}$ TEA (a competitive substrate of OCT family transporters) was reduced to $65 \pm 12 \%$ of the transported concentration without TEA for both fat-free and AA treated cells (data not shown) and no significant difference was observed in the transport reduction between fat-free and AA treated cells, thus indicating that the changes in membrane fluidity only concern the tight junctions and do not impact on drug transporter function. The effect of saturated fatty acids on bronchodilator transport requires further investigation. Importantly, the concentration of AA that was used in this study is physiologically relevant. In humans, levels of total free fatty acids in blood plasma are approximately $500 \mu \mathrm{M}$. AA accounts for around $10 \%$ of these total circulating free fatty acids, i.e. free AA concentrations in plasma are approximately $50 \mu \mathrm{M} .^{31,32}$

In conclusion, very distinct changes in the surface morphology and stiffness of Calu-3 bronchial epithelial cells were seen after the addition of AA. In general, an increase in homology was observed with a concurrent decrease in cell wall stiffness. Such observations were associated with an increase in the transport of salbutamol sulphate across this cell line. Whether this is due to an increase in cell membrane fluidity resulting in modification of either/or transcellular/paracelluar transport or through modification of membrane-bound transport proteins via conformation changes in the bilayer requires further investigation.

Although in the present study only the transport of SS was investigated, it is possible to assume that similar effects would be observed with other drugs with similar physicochemical characteristics as that of SS. However, since there are differences in the lipophilicity of the $\beta 2$-agonist family, we do not expect to see the same results in transport of other $\beta 2$-agonists following exposure to AA.

\section{Abbreviations}

PUFA Polyunsaturated fatty acids

AA Arachidonic acid
SS

AFM

TEER

flu-Na

HBSS

HPLC

OCTs

\section{Acknowledgements}

L. Wood; B. Oliver; P. M. Young; D. Traini. Fatty acids and bronchodilator responses in asthma. Thoracic Society of Australia and New Zealand Novartis/TSANZ Lung Health Research Grant-In-Aid Award.

\section{References}

1 D. B. Jump, The Biochemistry of N-3 Polyunsaturated Fatty Acids, J. Biol. Chem., 2002, 277, 8755-8758.

2 C. A. Dise, D. B. Goodman and H. Rasmussen, Definition of the Pathway for Membrane Phospholipid Fatty Acid Turnover in Human Erythrocytes, J. Lipid Res., 1980, 21, 292-300.

3 L. G. Wood, M. L. Garg and P. G. Gibson, A High-Fat Challenge Increases Airway Inflammation and Impairs Bronchodilator Recovery in Asthma, J. Allergy Clin. Immunol., 2011, 127, 1133-1140.

4 J. Helenius, C.-P. Heisenberg, H. E. Gaub and D. J. Muller, Single-Cell Force Spectroscopy, J. Cell Sci., 2008, 121, 17851791.

5 X. Cai, X. Xing, J. Cai, Q. Chen, S. Wu and F. Huang, Connection between Biomechanics and Cytoskeleton Structure of Lymphocyte and Jurkat Cells: An Afm Study, Micron, 2010, 41, 257-262.

6 D. Kirmizis and S. Logothetidis, Atomic Force Microscopy Probing in the Measurement of Cell Mechanics, Int. J. Nanomed., 2010, 5, 137-145.

7 M. Li, L. Liu, N. Xi, Y. Wang, Z. Dong, X. Xiao and W. Zhang, Atomic Force Microscopy Imaging and Mechanical Properties Measurement of Red Blood Cells and Aggressive Cancer Cells, Sci. China: Life Sci., 2012, 55, 968-973.

8 R. Yang, N. Xi, K. Wai Chiu Lai, K. C. Patterson, H. Chen, B. Song, C. Qu, B. Zhong and D. H. Wang, Cellular Biophysical Dynamics and Ion Channel Activities Detected by Afm-Based Nanorobotic Manipulator in Insulinoma BCells, Nanomedicine: Nanotechnology, Biology and Medicine, 2013, 9, 636-645.

9 M. Radmacher, Studying the Mechanics of Cellular Processes by Atomic Force Microscopy, Methods Cell Biol., 2007, 83, 347-372.

10 W. Xu, R. Mezencev, B. Kim, L. Wang, J. McDonald and T. Sulchek, Cell Stiffness Is a Biomarker of the Metastatic Potential of Ovarian Cancer Cells, PLoS One, 2012, 7, e46609.

11 C. D. Stubbs and A. D. Smith, The Modification of Mammalian Membrane Polyunsaturated Fatty Acid Composition in Relation to Membrane Fluidity and 
Function, BBA, Biochim. Biophys. Acta, Rev. Biomembr., 1984, 779, 89-137.

12 A. Sinclair and K. O'Dea, The Significance of Arachidonic Acid in Hunter-Gatherer Diets: Implications for the Contemporary Western Diet, J. Food Lipids, 1993, 1, 143-157.

13 C. von Schacky, S. Fischer and P. C. Weber, Long-Term Effects of Dietary Marine Omega-3 Fatty Acids Upon Plasma and Cellular Lipids, Platelet Function, and Eicosanoid Formation in Humans, J. Clin. Invest., 1985, 76, 1626-1631.

14 A. R. Brash, Arachidonic Acid as a Bioactive Molecule, J. Clin. Invest., 2001, 107, 1339-1345.

15 D. D'Sa, H.-K. Chan and W. Chrzanowski, Predicting Physical Stability in Pressurized Metered Dose Inhalers via Dwell and Instantaneous Force Colloidal Probe Microscopy, Eur. J. Pharm. Biopharm., 2014, 88, 129-135.

16 H.-J. Butt, B. Cappella and M. Kappl, Force Measurements with the Atomic Force Microscope: Technique, Interpretation and Applications, Surf. Sci. Rep., 2005, 59, 1152.

17 H. K. Webb, V. Khanh Truong, J. Hasan, R. J. Crawford and E. P. Ivanova, Physico-Mechanical Characterisation of Cells Using Atomic Force Microscopy-Current Research and Methodologies, J. Microbiol. Methods, 2011, 86, 131-139.

18 M. Mamlouk, P. M. Young, M. Bebawy, M. Haghi, S. Mamlouk, V. Mulay and D. Traini, Salbutamol Sulfate Absorption across Calu-3 Bronchial Epithelia Cell Monolayer Is Inhibited in the Presence of Common Anionic Nsaids, J. Asthma, 2013, 50, 334-341.

19 M. Haghi, P. M. Young, D. Traini, R. Jaiswal, J. Gong and M. Bebawy, Time- and Passage-DependentCharacteristics of a Calu-3 Respiratory Epithelial Cell Model, Drug Dev. Ind. Pharm., 2010, 36, 1207-1214.

20 H. Hertz, Ueber Den Kontakt Elastischer Koerper, J. Reine Angew. Math., 1881, 92, 156-171.

21 A. Collinsworth, S. Zhang, W. Kraus and G. Truskey, Apparent Elastic Modulus and Hysteresis of Skeletal Muscle Cells Throughout Differentiation, Am. J. Physiol.: Cell Physiol., 2002, 283, C1219-C1227.
22 S. Lieber, N. Aubry, J. Pain, G. Diaz, S. Kim and S. Vatner, Aging Increases Stiffness of Cardiac Myocytes Measured by Atomic Force Microscopy Nanoindentation, Am. J. Physiol.: Heart Circ. Physiol., 2004, 287, H645-H651, Epub 2004 Mar 25.

23 S. Scalia, M. Haghi, V. Losi, V. Trotta, P. M. Young and D. Traini, Quercetin Solid Lipid Microparticles: A Flavonoid for Inhalation Lung Delivery, Eur. J. Pharm. Sci., 2013, 49, 278-285.

24 R. R. Brenner, Effect of Unsaturated Acids on Membrane Structure and Enzyme Kinetics, Prog. Lipid Res., 1984, 23, 69-96.

25 W. Stillwell and S. R. Wassall, Docosahexaenoic Acid: Membrane Properties of a Unique Fatty Acid, Chem. Phys. Lipids, 2003, 126, 1-27.

26 X. Yang, W. Sheng, G. Y. Sun and J. C. M. Lee, Effects of Fatty Acid Unsaturation Numbers on Membrane Fluidity and ASecretase-Dependent Amyloid Precursor Protein Processing, Neurochem. Int., 2011, 58, 321-329.

27 S. Jong, Triacylglycerol Crystal Structures and Fatty Acid Conformations. A Theoretical Approach, 1980.

28 W. Dowhan and M. Bogdanov, Lipid-Protein Interactions as Determinants of Membrane Protein Structure and Function, Biochem. Soc. Trans., 2011, 39, 767-774.

29 H. J. Unwalla, G. Horvath, F. D. Roth, G. E. Conner and M. Salathe, Albuterol Modulates Its Own Transepithelial Flux via Changes in Paracellular Permeability, Am. J. Respir. Cell Mol. Biol., 2012, 46, 551-558.

30 M. Haghi, D. Traini, M. Bebawy and P. M. Young, Deposition, Diffusion and Transport Mechanism of Dry Powder Microparticulate Salbutamol, at the Respiratory Epithelia, Mol. Pharm., 2012, 9, 1717-1726.

31 H. O. Steinberg, M. Tarshoby, R. Monestel, G. Gook, J. Cronin, A. Johnson, B. Bayazeed and A. D. Baron, Elevated Circulating Free Fatty Acid Levels Impair Endothelium-Dependent Vasodilation, J. Clin. Invest., 1997, 100, 1230-1239.

32 K. Yuki, I. Kimura and K. Tsubota, Serum Free Fatty Acids Levels Not Associated with Normal Tension Glaucoma, Clin. Ophthalmol., 2010, 4, 91-94. 